\title{
Human papillomavirus oncogenic expression in the dysplastic portio; an investigation of biopsies from 190 cervical cones
}

\author{
I Kraus*, ', T Molden', LE Ernø ${ }^{3}$, H Skomedal ${ }^{2}$, F Karlsen ${ }^{2}$ and B Hagmar' \\ IInstitute of Pathology, The National University Hospital, 0027 Oslo, Norway; ${ }^{2}$ NorChip, 3490 Klokkarstua, Norway; ${ }^{3}$ Department of Gynaecology and \\ Obstetrics, Østfold County Hospital, 1603 Fredrikstad, Norway
}

\begin{abstract}
In this study, we investigated the presence of E6/E7 transcripts of seven common high-risk human papillomavirus (HPV) types in I90 cervical biopsies. The RNA-based real-time nucleic acid sequence-based amplification assay (NASBA) and type-specific PCR, both detecting HPV 16, I8, 31, 33, 45, 52, and 58, as well as consensus PCR, were performed on all 190 biopsies. High accordance between type-specific and consensus PCR confirms that the HPV types included in this study are the most common types present in cervical dysplasia. Furthermore, we see a clear increase in the incidence of HPV, both DNA and RNA, along with the histological severity of dysplasia. HPV RNA was detected in all but two PCR-positive cases, confirming that the virus exerts E6/E7 mRNA expression in cases of high-grade dysplasia. Out of 19 women given a normal or borderline diagnosis at conisation, only four were found HPV positive, which may suggest that unnecessary conisations can possibly be reduced by introducing HPV testing into the preoperative routine assessment.
\end{abstract}

British Journal of Cancer (2004) 90, |407- |4|3. doi:I0.1038/sj.bjc.660 I69 I www.bjcancer.com

Published online 2 March 2004

(c) 2004 Cancer Research UK

Keywords: human papillomavirus (HPV); oncogene; gene expression; NASBA; PCR; cervical intraepithelial neoplasia (CIN)

Human papillomavirus (HPV) infections are associated with the development of cervical neoplasia and are a necessary factor in the aetiology of cervical carcinoma (Walboomers et al, 1999; Bosch et al, 2002; zur Hausen, 2002). The most frequent HPV types found in high-grade cervical intraepithelial dysplasia (CIN II/III) and in cervical carcinomas are HPV 16, 18, 31,33, and 45, which are often referred to as high-risk HPV or cancer-associated HPV types. However, the association between a positive HPV DNA test and the risk of subsequent development of dysplasia is partly unknown; the presence of HPV DNA does not necessarily indicate a risk for developing a more severe lesion. In fact, HPV is a very common virus among sexually active women and most infections are transient and asymptomatic (zur Hausen, 1991; Ho et al, 1998; Moscicki et al, 1998). Only very few infections cause morphologic changes in the epithelium and only a small percent of these will eventually develop cervical cancer (Bosch et al, 1995). On the other hand, several studies have shown that in cervical carcinogenesis, the expression of HPV E6 and E7 ORF is required for cell transformation and immortalisation (zur Hausen, 1988; Munger et al, 1989; Stoler et al, 1992). Consequently, persistent expression of these oncogenes may serve as an indicator of progression to CIN and invasive cancer (Sotlar et al, 1998), and detection of E6 and E7 mRNA transcripts may therefore be of higher prognostic value than the detection of HPV DNA. Moreover, new methods for preservation of RNA in cells have made gene expression analysis more feasible.

\footnotetext{
*Correspondence: I Kraus, The National University Hospital, 0027 Oslo Norway; E-mail: h.i.kraus@labmed.uio.no

Received 2 July 2003; revised 17 November 2003; accepted 7 January 2004; published online 2 March 2004
}

In this study, we investigated the presence of high-risk HPV E6/E7 transcripts in cervical biopsies from patients undergoing conisation. The analysis was performed on a biopsy taken from the ectocervix/transformation zone at the time of conisation, and the pathological diagnosis of this particular biopsy was not always representative for the existing lesion that was later revealed in the cone. This strategy gave us access to a uniformly preserved material with varying degrees of squamous cell dysplasia, yet from cones that in most cases harboured a CIN III lesion. For RNA detection, the RNA-based real-time nucleic acid sequence-based amplification assay (NASBA) was used, focusing on the reportedly most common oncogenic HPV types $16,18,31$, 33, 45, 52, and 58 (Walboomers et al, 1999; Munoz et al, 2003). Results were compared with cytologic and histopathologic findings, and HPV DNA status as assessed by consensus and type-specific PCR.

\section{MATERIALS AND METHODS}

\section{Cell culture}

The cervical carcinoma cell lines SiHa (squamous cell carcinoma), CaSki (squamous cell carcinoma), and HeLa (adenocarcinoma), used as positive controls, were obtained from the American Type Culture Collection, USA. The SiHa and HeLa cell lines were maintained in Dulbecco's modified Eagle's medium (DMEM), CaSki cells in RPMI medium, supplemented with $10 \%$ fetal bovine serum (FBS), $2 \mathrm{~mm}$ L-glutamine, and $25 \mu \mathrm{g} \mathrm{ml}^{-1}$ gentamicin. The cells were incubated at $37^{\circ} \mathrm{C}$ in a $5 \% \mathrm{CO}_{2}$ atmosphere. The cells were harvested directly in lysis buffer (bioMérieux, the Netherlands, containing $5 \mathrm{~m}$ guanidine thiocyanate). 


\section{Patients/clinical samples}

The study was performed on 190 consecutive biopsies, taken from 190 women admitted to Østfold County Hospital for treatment of CIN during the period October 1999 to October 2001. The mean age at diagnosis was 37.4 years (range $22-74$ years). Biopsies were frozen at $-70^{\circ} \mathrm{C}$ immediately after collection. All women were subjected to subsequent conisation.

\section{Cytological and histological examination of samples}

Initially, routine cytological grading was performed according to local routine guidelines. No review cytology was performed. After a high-grade cytology report, or an equivocal cytological smear, the patients were referred to colposcopy and biopsy (Østfold County Hospital). Iodine painting of the portio was used as a means of visualising dysplasia. Multiple biopsies were taken from the external os and from any colposcopically pathological lesion. In addition, the cervical canal was scraped. If these biopsies (Biopsy 1/Histology 1, Table 1) confirmed a high-grade lesion (CIN II/III), the patient was again admitted to hospital, this time for conisation. In some cases, the patients were referred to conisation on the basis of an unclear diagnosis or a long-lasting persistent CIN I lesion. For these cases, only a diagnostic cone was taken, as small as possible. If the woman did not plan for future pregnancy, a combined diagnostic and therapeutic conisation was performed. Before conisation, but after local anaesthesia was applied, a single biopsy (Biopsy 2/Histology 2b, Table 1) was taken from the ectocervix. This biopsy $(2 \times 2 \mathrm{~mm})$ was frozen within $2 \mathrm{~min}$ at $-70^{\circ} \mathrm{C}$. Biopsy 2 was split in two when frozen, and half was used for DNA/RNA extraction. The other half was fixed in $10 \%$ buffered formaldehyde and processed for histopathological examination. Some lesions were not correctly oriented in the paraffin block and had to be reoriented or serial sectioned in order to show the relevant surface epithelium. Consequently, it cannot be guaranteed that the histopathological diagnosis reflect the actual condition of the tissue used for extraction. Finally, the cone specimen was evaluated by a histopathologist, who subsequently confirmed or disproved the presence and severity of dysplasia (Histology 3, Table 1).

\section{Extraction of nucleic acids}

Nucleic acids were isolated using the automated NucliSens Extractor (bioMérieux, the Netherlands) as previously described (Boom et al, 1990). Briefly, the material was divided into smaller pieces while kept on dry ice $\left(-80^{\circ} \mathrm{C}\right)$ and subsequently transferred to $1 \mathrm{ml}$ of lysis buffer (bioMérieux) followed by $20 \mathrm{~s}$ of homogenisation using disposable pestles, after which $100 \mu \mathrm{l}$ of the sample was further diluted 10-fold in lysis buffer. A $100 \mu \mathrm{l}$ volume was then used for the DNA/RNA extraction, which resulted in a final elution volume of $-40 \mu \mathrm{l}$. Extracts were stored at $-70^{\circ} \mathrm{C}$.

\section{NASBA protocol: amplification and detection of HPV RNA}

Human papillomavirus RNA was detected by real-time NASBA (Compton, 1991; Chan and Fox, 1999; Deiman et al, 2002). Reagents were obtained from NorChip (Klokkarstua, Norway), as they are presented in the commercially available PreTect HPVProofer kit. Briefly, NASBA is based on isothermal RNA amplification, accomplished by the simultaneous enzymatic activity of avian myeloblastosis virus (AMV) reverse transcriptase, T7 RNA polymerase, and RNase H (Compton, 1991). For detection we used primers and molecular beacon (MB) probes directed against E6/E7 mRNA for HPV types 16, 18, 31, 33, 45, 52, and 58 (NorChip, Klokkarstua, Norway). Final concentration of MBs used in the reaction was $2.5 \mathrm{~mm}$. The NASBA amplification was carried out in a volume of $20 \mu \mathrm{l}$ at $41^{\circ} \mathrm{C}$ for $2 \mathrm{~h}$. A $5 \mu \mathrm{l}$ volume of nucleic acids, diluted five times after extraction, was included in the reaction. As performance control, to avoid false negatives due to degradation of nucleic acid, we used a primerset and probe directed against the human U1 small nuclear ribonucleoprotein (snRNP)-specific A protein (U1A mRNA) (Compton, 1991; Nelissen et al, 1991). All samples were run in duplicate on separate microplate readers (Lambda FL-600, Bio-Tek Instruments, Winooski, USA). RNA isolated from CaSki/SiHa or HeLa cells served as positive controls for HPV 16 and HPV 18 transcripts, respectively. For the other HPV types, these cell lines were used as negative controls. In addition, negative controls consisting of all reagents except RNA were included for every seventh reaction.

\section{Human papillomavirus DNA analysis: polymerase chain reaction}

The same nucleic acid extracts and amounts as used in the NASBA reaction were used for HPV DNA PCR. The L1 consensus primers $\mathrm{Gp} 5+/ \mathrm{Gp} 6+$ (Roda Husman et al, 1995) were used to assess the samples that contained HPV DNA. The PCR amplification was carried out in a volume of $50 \mu \mathrm{l}$ containing as final concentrations $75 \mathrm{~mm}$ Tris- $\mathrm{HCl}$ (pH 8.8), 0.01\% Tween, $20 \mathrm{~mm}\left(\mathrm{NH}_{4}\right)_{2} \mathrm{SO}_{4}, 1.5 \mathrm{~mm}$ $\mathrm{MgCl}_{2}, 0.2 \mathrm{~mm}$ dNTPs, $50 \mathrm{pmol}$ of $\mathrm{Gp} 5+$ and Gp6 + primers, and $1.0 \mathrm{U}$ of Taq DNA polymerase (Sigma-Aldrich, Missouri, USA). Human papillomavirus DNA was amplified by using a thermo cycler heat block from MWG, Ebersberg, Germany (Primus 96 HPL

Table I Cytology and histology results

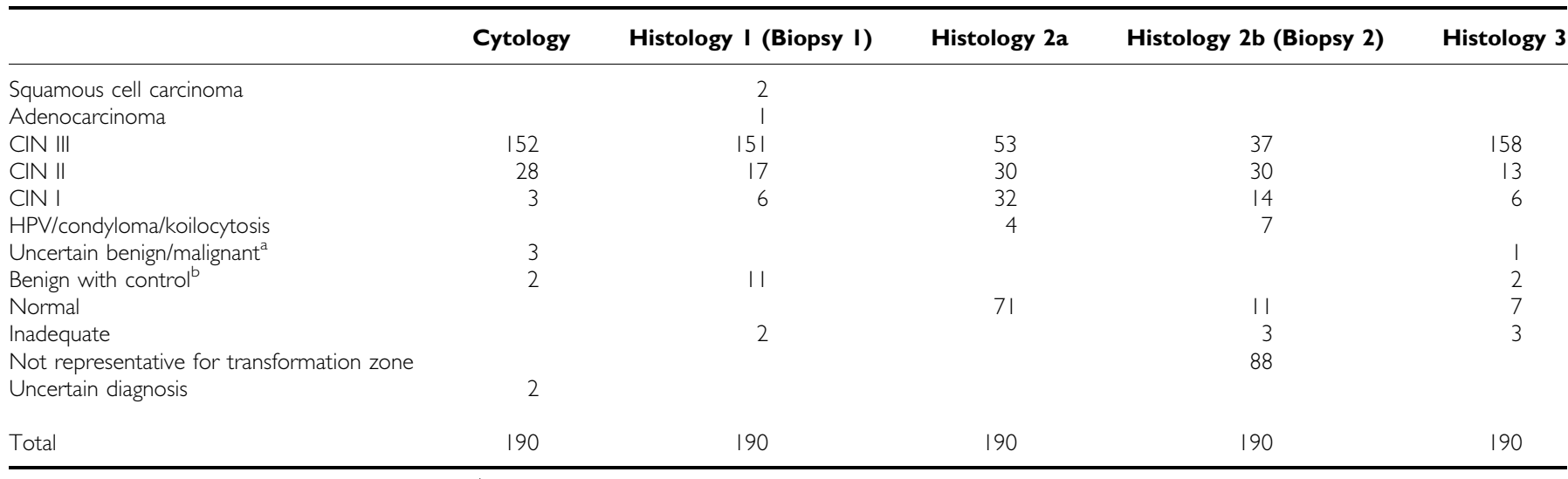

${ }^{a}$ Corresponding to Bethesda nomenclature ASC-H. ${ }^{b}$ Corresponding to Bethesda nomenclature ASC-US. 
block). The first DNA denaturation was carried out for $2 \mathrm{~min}$ at $94^{\circ} \mathrm{C}$, followed by 40 cycles of denaturation for $1 \mathrm{~min}$ at $94^{\circ} \mathrm{C}$, annealing for $2 \mathrm{~min}$ at $40^{\circ} \mathrm{C}$, and extension for $1.5 \mathrm{~min}$ at $72^{\circ} \mathrm{C}$, prior to a final extension for $4 \mathrm{~min}$ at $72^{\circ} \mathrm{C}$. Genotyping of HPV was performed by using PCR type-specific primers against HPV types 16, 18, 31, 33, 45, 52, and 58 (NorChip, Klokkarstua, Norway), utilising $25 \mathrm{pmol}$ of each primer. The PCR conditions were 35 cycles of denaturation for $0.5 \mathrm{~min}$ at $94^{\circ} \mathrm{C}$, annealing $0.5 \mathrm{~min}$ at $57^{\circ} \mathrm{C}$, and extension for $1 \mathrm{~min}$ at $72^{\circ} \mathrm{C}$. For a cellular control, we used primers against the human $\beta$-globin gene (Mwenda et al, 1999). DNA isolated from CaSki/SiHa or HeLa cells served as positive controls for HPV 16 and HPV 18, respectively. For the other HPV types, these cell lines were used as negative controls. Negative controls, consisting of all reagents except DNA, were included for every seventh reaction. Fragments were visualised by using the 2100 Bioanalyzer Multi-Instrument system (Agilent Technologies, CA, USA).

\section{DNA sequencing}

Samples that tested HPV DNA positive with the consensus primers yet negative with type-specific PCR primers were sequenced in order to determine the HPV type. Sequencing was performed at the University of Oslo (Norway) by the MegaBACE Sequence Analyzer (Amersham Biosciences, Little Chalfont, England) according to in-house protocols. Sequence comparisons were performed using BLAST.

\section{RESULTS}

\section{Cytology and histology}

Table 1 summarises the clinical diagnoses of patients included in the study. According to cytology, 180 out of 190 patients had indications of high-grade dysplasia (CIN II or III); eight had repeatedly the diagnosis of mild or low-grade abnormalities, and two patients had an equivocal cytological smear. In all cases, the cytological report was the basis for subsequent hospital admittance, colposcopy and biopsy (Histology 1, Table 1). A high-grade lesion (CIN II or III) was in 168 out of 190 cases confirmed by histological examination. All patients having a high-grade lesion either at cytology or histology were admitted for conisation. In addition, some patients were admitted for conisation on the basis of equivocal cytology and histology. Biopsy 2, taken at conisation (Histology 2b, Table 1), was used for RNA analysis. Only one biopsy was taken, and because local anaesthesia made it difficult to locate the lesion by colposcopy, this biopsy was not always representative for an existing CIN lesion that was later revealed in the cone. This biopsy was examined twice by a pathologist who was blinded to the subject's HPV status. The first histological examination (Histology 2a, see Table 1) diagnosed only 83 samples of the original 168 as CIN II/III, 32 as CIN I, and four as HPV/ condyloma. In 71 samples, high-grade lesions were not detected. Re-examination of the slide, to check for representativeness (Histology 2b), revealed 88 of the biopsies as not representative, that is, the tissue was not taken from the transformation zone; CIN III was found in 37 cases, CIN II in 30 cases, and CIN I in 14 cases. Conisation confirmed 158 of the women to harbour a CIN III lesion, 13 having CIN II. As many as 19 women had a low-grade or equivocal diagnosis at conisation (Table 1): six were diagnosed as CIN I, three as nonrepresentative, and 10 were diagnosed as benign or normal. Almost all of these women were given a high-grade diagnosis at cytology, but were given a low-grade/benign diagnosis at the first histological examination (Histology 1); four of these 19 women were found to be HPV positive (Table 2).

\section{Human papillomavirus RNA and DNA in CIN}

Human papillomavirus E6/E7 transcripts from HPV 16, 18, 31, 33, 45,52 , and 58 were detected in 88 out of $190(46 \%)$ biopsies, of which 83 out of $88(94 \%)$ represented HPV 16, 18, 31,33, and 45. Of the 37 samples diagnosed as CIN III (Histology 2b) 34 cases (92\%) showed E6/E7 expression, only representing HPV 16, 18, 31, 33 , and 45 . In addition, we found oncogenic expression in 16 out of 30 cases $(53 \%)$ with CIN II. No CIN I cases $(n=14)$ were found to contain HPV RNA. Transcripts were also found in two out of seven cases of borderline samples, in two out of 11 cases not showing dysplasia, and in three samples being histologically inadequate. Among the 88 nonrepresentative samples, we detected HPV RNA in 31 samples $(35 \%)$. Results are presented in Figure 1. Figure 2 shows a typical RNA amplification curve as measured by real-time NASBA, exemplified by an HPV 16-positive sample.

In order to investigate the prevalence of HPV DNA vs RNA in the cervical biopsies, and to evaluate the analytical specificity and

Table 2 Samples diagnosed as normal or borderline at conisation (Histology 3), including previous cytological and histological diagnoses, as well as NASBA and PCR results

\begin{tabular}{|c|c|c|c|c|c|c|c|}
\hline Cytology & Histology I (Biopsy I) & Histology $2 a$ & Histology 2b (Biopsy 2) & Histology 3 & NASBA & PCR & Gp5+6+ \\
\hline CIN III & Benign with control & Normal & Nonrepresentative & Normal & - & - & - \\
\hline CIN III & Benign with control & Normal & Normal & Normal & - & - & - \\
\hline CIN III & Benign with control & CIN I & Nonrepresentative & Normal & - & - & - \\
\hline CIN III & Benign with control & CIN I & Nonrepresentative & Normal & - & - & - \\
\hline CIN III & Benign with control & CIN I & Nonrepresentative & Normal & 31 & 31 & + \\
\hline CIN II & Benign with control & Normal & Nonrepresentative & Normal & - & - & - \\
\hline CIN III & Benign with control & CINI & Nonrepresentative & Normal & - & - & - \\
\hline CIN III & Inadequate & CIN I & $\mathrm{CINI}$ & Inadequate & - & - & - \\
\hline Uncertain benign & Inadequate & Normal & Nonrepresentative & Inadequate & - & - & - \\
\hline Uncertain benign & CIN III & Normal & Normal & Inadequate & - & - & - \\
\hline CIN III & Benign with control & Normal & Nonrepresentative & Benign with control & - & - & - \\
\hline CIN III & Benign with control & $\mathrm{CINI}$ & HPV & Benign with control & - & - & $+^{\mathrm{a}}$ \\
\hline CIN II & Benign with control & Normal & Nonrepresentative & Uncertain benign & 16 & 16 & + \\
\hline CIN \| & CINI & Normal & Nonrepresentative & CINI & - & - & - \\
\hline CIN I & CIN I & CIN \| & Koilocytosis & CINI & - & - & - \\
\hline CIN III & CIN I & CIN I & Nonrepresentative & CIN I & - & - & - \\
\hline CIN III & CIN I & CIN I & Nonrepresentative & CINI & - & - & - \\
\hline CIN III & CIN I & Normal & Normal & CIN I & 16 & 16 & + \\
\hline CIN III & CIN I & Normal & Normal & CIN I & - & - & - \\
\hline
\end{tabular}

aBy sequencing revealed as HPV 35; - negative test result; Non-representative = not representative for the transformation zone. 
sensitivity of the NASBA method, we also performed PCR on the same 190 biopsies, both by type-specific and consensus PCR. Results are summarised in Table 3. Type-specific PCR, directed against E6/E7 for the HPV types 16, 18, 31, 33, 45, 52, and 58,

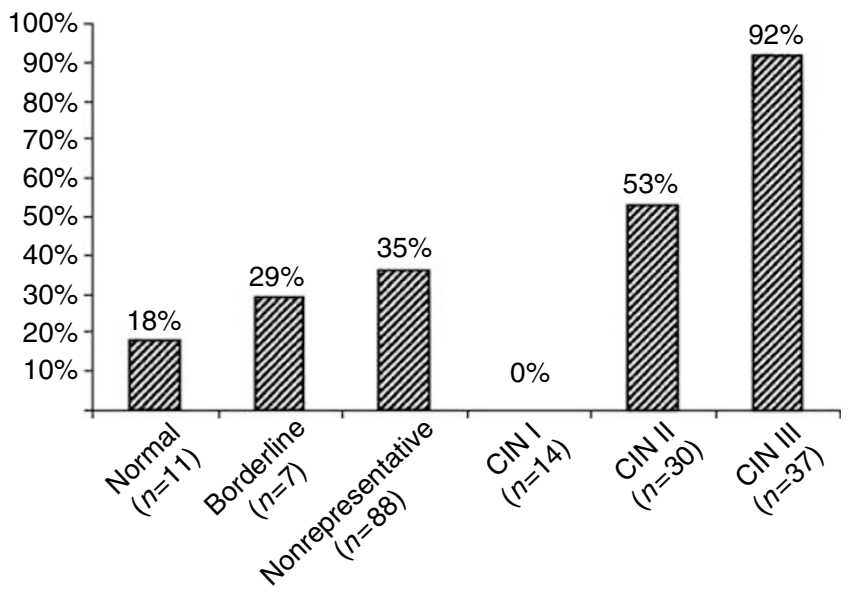

Figure I Oncogenic HPV activity detected by real-time NASBA. The presence of HPV DNA and RNA increased with the histological severity of the cervical intraepithelial neoplasia (CIN). HPV was also detected in samples with histological diagnosis normal, borderline, or nonrepresentative. The respective values in percentage are indicated above each bar. Borderline samples include HPV, condyloma, and koilocytosis.

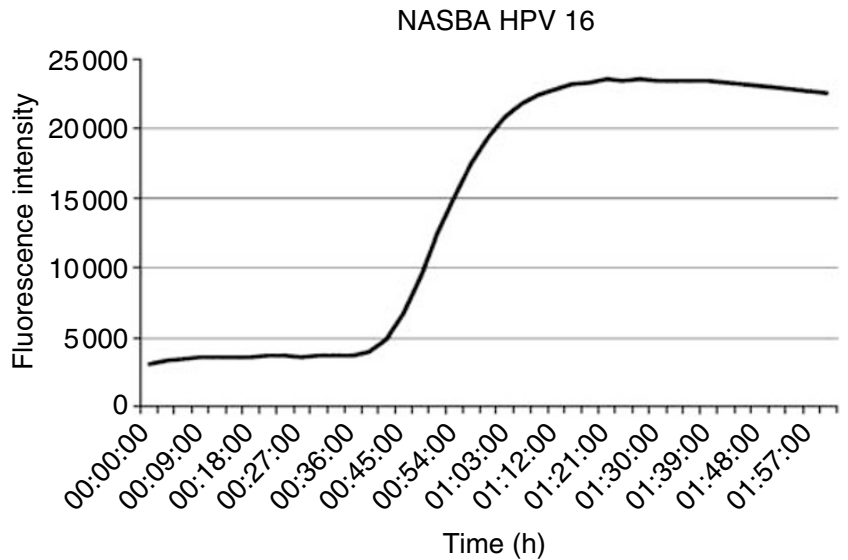

Figure 2 Amplification of HPV RNA by real-time NASBA. A positive reaction result is revealed as a sigmoid curve. detected 90 samples containing HPV, of which all but two were positive by NASBA. Using the consensus $\mathrm{Gp} 5+/ \mathrm{Gp} 6+$ primers directed against the L1 gene, PCR detected HPV in 85 out of 190 biopsies, of which five were not detected by type-specific PCR. In addition, 10 samples that were positive by type-specific PCR were not detected by using consensus primers. In total, taking both consensus and type-specific PCR into account, PCR found 95 samples HPV positive.

The expression pattern for the different HPV types according to CIN grade is summarised in Table 4. Human papillomavirus 16 was the most common type found ( 50 out of 88 ), followed by HPV 31 (14 out of 88), HPV 33 (nine out of 88), HPV 18 (seven out of 88), HPV 45 (seven out of 88), HPV 52 (three out of 88), and HPV 58 (three out of 88). Five patients had multiple infections, all with a high-grade CIN diagnosis (CIN II or III): one patient had mixed expression of HPV 16 and HPV 18, one of HPV 16 and HPV 31, two of HPV 16 and HPV 33, and one of HPV 33 and HPV 58. HPV 52 and 58 were not detected in any CIN III cases. Table 5 shows the distribution of HPV types for different age groups.

\section{DNA sequencing}

The five samples positive by consensus PCR, yet negative by typespecific PCR and NASBA, were typed by sequencing. Three samples were revealed as HPV 35 (one CIN III, one borderline, one nonrepresentative), one sample as HPV 51 (nonrepresentative), and one sample as HPV 67 (CIN II).

\section{DISCUSSION}

To our knowledge, this is the first study performing HPV mRNA analysis for several HPV types on a large number of histologically confirmed lesions. By comparing the RNA technology NASBA with conventional PCR of HPV DNA, this study permitted us to evaluate HPVs oncogenic activity in different grades of dysplasia. With a few exceptions, all patients included in the study were originally given a high-grade CIN diagnosis (CIN II/III) by cytological examination and/or by the first histological examination (Biopsy 1). However, the RNA analysis was performed on a separate biopsy (Biopsy 2), taken from the ectocervix/transformation zone at conisation. Only one biopsy was taken, and because local anaesthesia made it difficult to locate the lesion by colposcopy, this biopsy was not always representative for an existing CIN II/III lesion that was later revealed in the cone.

Biopsy 2 was examined twice histologically, in order to grade any dysplasia and to define samples not representative for the transformation zone, that is, samples containing only tissue from portio, external to the os (Histology $2 \mathrm{a}$ vs $2 \mathrm{~b}$, Table 1). The

Table 3 NASBA results shown according to PCR positives and negatives (both consensus and type-specific), for each of the histological categories

\begin{tabular}{|c|c|c|c|c|}
\hline \multirow{2}{*}{ Histology 2b } & \multicolumn{2}{|c|}{ PCR positives $(n=95)$} & \multicolumn{2}{|c|}{ PCR negatives $(n=95)$} \\
\hline & No. of NASBA positives & No. of NASBA negatives & No. of NASBA positives & No. of NASBA negatives \\
\hline CIN $\|(n=30)$ & 16 & $1^{b}$ & 0 & 13 \\
\hline $\mathrm{CINI}(n=14)$ & 0 & $j^{c}$ & 0 & 13 \\
\hline Borderline $^{d}(n=7)$ & 2 & $\mathrm{I}^{\mathrm{e}}$ & 0 & 4 \\
\hline Normal $(n=||)$ & 2 & 0 & 0 & 9 \\
\hline Total $(n=190)$ & 88 & 7 & 0 & 95 \\
\hline
\end{tabular}

Non-representative $=$ not representative for the transformation zone. ${ }^{a} \mathrm{HPV}$ I6+HPV35. ${ }^{\mathrm{b}} \mathrm{HPV} 67$. ${ }^{\mathrm{H}} \mathrm{HPVI}$. ${ }^{\mathrm{d}}$ Borderline samples include HPV, condyloma, and koilocytosis, eHPV35. fHPV35+HPV5I. 
Table 4 Distribution of different HPV types detected by NASBA

\begin{tabular}{|c|c|c|c|c|c|c|c|}
\hline & \multicolumn{7}{|c|}{ HPV types } \\
\hline $\mathrm{CIN}$ III & 25 & 3 & 4 & 3 & 2 & & \\
\hline $\mathrm{CIN} \|$ & 8 & 1 & 2 & 4 & 1 & 1 & 1 \\
\hline Borderline & I & & & & & & 1 \\
\hline Normal & 1 & & & & & & I \\
\hline Inadequate & 2 & & & & & 1 & \\
\hline Total $(n=88)$ & 50 & 7 & 14 & 9 & 7 & 3 & 3 \\
\hline
\end{tabular}

Distribution of the seven high-risk HPV types determined by NASBA in the biopsies taken at conisation (Histology 2b). The total number is summarised to 93 due to multiple infections in five cases. Nonrepresentative = not representative for the transformation zone.

Table 5 Distribution of high-risk HPV RNA for the age groups indicated

\begin{tabular}{|c|c|c|c|c|c|c|c|c|}
\hline Year of birth & $\begin{array}{l}\text { No. of women } \\
\quad(n=190)\end{array}$ & HPV 16 & HPV I 8 & HPV 3 I & HPV 33 & HPV 45 & HPV 52 & HPV 58 \\
\hline $1926-1949$ & 23 & 7 & 2 & 0 & 0 & 0 & 0 & I \\
\hline $1950-1959$ & 32 & 8 & I & I & I & 2 & 0 & 2 \\
\hline $1960-1969$ & 70 & 20 & 2 & 4 & 4 & 3 & 3 & 0 \\
\hline $1970-1979$ & 65 & 15 & 2 & 9 & 4 & 2 & 0 & 0 \\
\hline
\end{tabular}

majority of the biopsies showing discrepancies in Histology 2a vs $2 \mathrm{~b}$ presents small areas of metaplastic atypia, difficult to fit into the CIN groups (Geng et al, 1999; Montes et al, 1999; Ng et al, 2002; Zuna et al, 2002). The discrepancy in the relative frequency of 'normals' between Histology $2 \mathrm{a}$ and $2 \mathrm{~b}$ is due to the fact that in $2 \mathrm{~b}$ the emphasis was on representativeness for the transformation zone.

In the NASBA reaction, as well as in the type-specific PCR, we tested for the reportedly most common oncogenic HPV types 16, $18,31,33,45,52$, and 58 (Walboomers et al, 1999; Munoz et al, 2003). We revealed that all but two PCR-positive cases also showed E6/E7 transcription. This shows that, at the level of severe dysplasia, HPV exerts an oncogenic activity (Nakagawa et al, 2000). Of the 37 samples diagnosed as CIN III (Histology 2b), we found 34 cases (92\%) HPV RNA positive; three out of 37 CIN III cases did not show any oncogenic expression, one being PCR HPV 16 positive (Table 3 ). This sample may represent cell abnormalities prone to regression, as a consequence of HPV expression being switched off: regression of abnormal cytology in women with a positive HPV test at baseline is often associated with viral clearance (Nobbenhuis et al, 2001). This is, however, a field not widely explored and much remains to be learned about the mechanisms behind regression of cervical dysplasia. Furthermore, we see a clear increase in the incidence of HPV, both DNA and RNA, with the severity of the lesion (Figure 1), which is in accordance with previous studies (Sotlar et al, 1998; Nakagawa et al, 2000). The finding that no CIN I cases demonstrated HPV oncogenic expression suggests that, even in the presence of concominant CIN III in other areas, histologically defined CIN I may not be strictly related to HPV and precancerous disease (Crum et al, 1999). However, further studies are needed in order to confirm this assumption.

Human papillomavirus expression was not restricted to the CIN lesions. We also found oncogenic expression in two of 11 cases not showing dysplasia (Histology 2b, Table 1). In general, this may indicate a potential risk for the development of a high-grade lesion. In these cases, however, our finding most likely reflects the lesion confirmed by Histology 1, located in another part of the cervix. This indicates that the virus can be present in the cervix exerting an oncogenic activity before cell changes can be visualised histologically, supporting the view that the natural history of HPV includes periods before the manifestation of a cell abnormality (Moscicki et al, 1998; Nobbenhuis et al, 2001). Also among biopsies not representative for the transformation zone, as well as in inadequate samples, we detected a high rate of HPV DNA and RNA positivity (Figure 1).

In addition to type-specific PCR, we also tested the biopsies for HPV DNA using HPV consensus primers (Table 3). We made use of the primer set $\mathrm{Gp} 5+/ \mathrm{Gp} 6+$, which detected all but 10 of the samples found positive by type-specific PCR. The 'missed' cases may be attributed to the fact that consensus primers are not sufficiently sensitive to detect all cases of HPV infection, at least not the cases containing a low HPV copy number (Karlsen et al, 1996). Besides, the use of these consensus primers may leave some important oncogenic HPV types undetected because of loss of the L1 sequence during viral integration. In clinical practice this can be critical, since integrated HPV 16/18 DNA has been revealed in various stages of dysplasia (Nagao et al, 2002; Gallo et $a l, 2003)$ and is shown to be common in patients with cervical carcinomas (Park et al, 1997; Kalantari et al, 1998; Walboomers et al, 1999). Therefore, the use of type-specific PCR, directed against one of the early-region genes (preferentially E6 and E7), is always recommended. On the other hand, consensus PCR detected five cases not detected by type-specific PCR. These samples were by sequencing revealed as HPV 35, 51, and 67. Nevertheless, the high association between consensus and typespecific PCR/NASBA supports that the HPV types included in this study are the most common types present in cervical dysplasia (Bosch et al, 2002).

The problem of inter- and intraobserver variability in cytology and histopathology paves the way for additional objective strategies in detecting cervical cancer precursors. Moreover, current management protocols may in certain cases lead to overtreatment (Meijer et al, 1998). This problem is emphasised in the present study: at the final evaluation of the cone, as many as 19 of the women received either a normal, benign, or low-grade diagnosis at (Histologi 3, Table 2). Almost all of these women had a high-grade diagnosis at cytology, yet a low-grade diagnosis at the 
first histological examination (Table 2). Conisation of these women was performed on the basis of high-grade cytological diagnoses, assuming the histology as being nonrepresentative. Only four of these women were found HPV positive, although we have to take into account that 12 out of 19 biopsies on which the HPV analysis were performed, were found to be nonrepresentative for the transformation zone. Nevertheless, unnecessary conisations can possibly be reduced by introducing HPV testing into the routine assessment. This is especially important among young women, who plan for future pregnancy, and for whom conisation entails increased risk for premature birth.

In conclusion, this study shows that HPV DNA and RNA detection achieve a similar result in biopsies of severe dysplasia, strengthening the case that HPV E6/E7 gene expression is necessary for oncogenesis in this region (zur Hausen, 1989). In general, detection of HPV E6/E7 transcripts, in combination with HPV typing, may have significant potential in identifying women who may be at a heightened risk for developing cervical dysplasia. However, our study unfortunately does not lend itself to calculations of clinical sensitivity and specificity, because of patient material selection and the fact that a relatively low number of true cytological and histological negative cases were included in the study. Therefore, RNA-based strategies for HPV testing are currently being investigated both in a screening context and in longitudinal follow-up studies.

\section{ACKNOWLEDGEMENTS}

We thank Dr Kate Cuschieri for her comments and contribution to the English language. In addition, we acknowledge Einar Morland, NorChip, for statistical support, and Petter Grønn and Marit Øder Øye for valuable laboratorial help. This work has been partially supported by grants from the Norwegian Reseach Council.

\section{REFERENCES}

Boom R, Sol CJ, Salimans MM, Jansen CL, Wertheim-van Dillen PM, van der NJ (1990) Rapid and simple method for purification of nucleic acids. J Clin Microbiol 28: $495-503$

Bosch FX, Lorincz A, Munoz N, Meijer CJ, Shah KV (2002) The causal relation between human papillomavirus and cervical cancer. J Clin Pathol 55: 244-265

Bosch FX, Manos MM, Munoz N, Sherman M, Jansen AM, Peto J, Schiffman MH, Moreno V, Kurman R, Shah KV (1995) Prevalence of human papillomavirus in cervical cancer: a worldwide perspective. International Biological Study on Cervical Cancer (IBSCC) Study Group. J Natl Cancer Inst 87: 796-802

Chan AB, Fox JD (1999) NASBA and other transcription-based amplification methods for research and diagnostic microbiology. Med Microbiol 10: $185-196$

Compton J (1991) Nucleic acid sequence-based amplification. Nature 350: 91-92

Crum CP, Genest DR, Krane JF, Hogan C, Sun D, Bellerose B, Kostopoulou E, Lee KR (1999) Subclassifying atypical squamous cells in thin-prep cervical cytology correlates with detection of high-risk human papillomavirus DNA. Am J Clin Pathol 112: 384-390

Deiman B, van Aarle P, Sillekens P (2002) Characteristics and applications of nucleic acid sequence-based amplification (NASBA). Mol Biotechnol 20: $163-179$

Gallo G, Bibbo M, Bagella L, Zamparelli A, Sanseverino F, Giovagnoli MR, Vecchione A, Giordano A (2003) Study of viral integration of HPV-16 in young patients with LSIL. J Clin Pathol 56: 532-536

Geng L, Connolly DC, Isacson C, Ronnett BM, Cho KR (1999) A typical immature metaplasia (AIM) of the cervix: is it related to high-grade squamous intraepithelial lesion (HSIL)? Hum Pathol 30: $345-351$

Ho GY, Bierman R, Beardsley L, Chang CJ, Burk RD (1998) Natural history of cervicovaginal papillomavirus infection in young women. $\mathrm{N} \mathrm{Engl} \mathrm{J}$ Med 338: $423-428$

Kalantari M, Karlsen F, Kristensen G, Holm R, Hagmar B, Johansson B (1998) Disruption of the E1 and E2 reading frames of HPV 16 in cervical carcinoma is associated with poor prognosis. Int J Gynecol Pathol 17: $146-153$

Karlsen F, Kalantari M, Jenkins A, Pettersen E, Kristensen G, Holm R, Johansson B, Hagmar B (1996) Use of multiple PCR primer sets for optimal detection of human papillomavirus. J Clin Microbiol 34: $2095-2100$

Meijer CJ, Helmerhorst TJ, Rozendaal L, van der Linden JC, Voorhorst FJ, Walboomers JM (1998) HPV typing and testing in gynaecological pathology: has the time come? Histopathology 33: 83-86

Montes MA, Cibas ES, DiNisco SA, Lee KR (1999) Cytologic characteristics of abnormal cells in prior 'normal' cervical/vaginal papanicolaou smears from women with a high grade squamous intraepithelial lesion. Cancer 87: $56-59$

Moscicki AB, Shiboski S, Broering J, Powell K, Clayton L, Jay N, Darragh TM, Brescia R, Kanowitz S, Miller SB, Stone J, Hanson E, Palefsky J

(1998) The natural history of human papillomavirus infection as measured by repeated DNA testing in adolescent and young women. J Pediatr 132: $277-284$

Munger K, Phelps WC, Bubb V, Howley PM, Schlegel R (1989) The E6 and E7 genes of the human papillomavirus type 16 together are necessary and sufficient for transformation of primary human keratinocytes. J Virol 63: $4417-4421$

Munoz N, Bosch FX, de Sanjose S, Herrero R, Castellsague X, Shah KV, Snijders PJ, Meijer CJ (2003) Epidemiologic classification of human papillomavirus types associated with cervical cancer. $N$ Engl J Med 348: 518-527

Mwenda JM, Shotake T, Yamamoto T, Uchihi R, Bambra CS, Katsumata Y (1999) DNA typing of primate major histocompatibility complex (Mhc)-DQA1 locus by PCR and dot blot hybridization. Cell Mol Biol (Noisy -le-grand) 45: 1249-1256

Nagao S, Yoshinouchi M, Miyagi Y, Hongo A, Kodama J, Itoh S, Kudo T (2002) Rapid and sensitive detection of physical status of human papillomavirus type 16 DNA by quantitative real-time PCR. J Clin Microbiol 40: $863-867$

Nakagawa S, Yoshikawa H, Yasugi T, Kimura M, Kawana K, Matsumoto K, Yamada M, Onda T, Taketani Y (2000) Ubiquitous presence of E6 and E7 transcripts in human papillomavirus-positive cervical carcinomas regardless of its type. J Med Virol 62: 251-258

Nelissen RL, Sillekens PT, Beijer RP, Geurts van Kessel AH, van Venrooij WJ (1991) Structure, chromosomal localization and evolutionary conservation of the gene encoding human U1 snRNP-specific A protein. Gene 102: 189-196

Ng WK, Cheung LK, Li AS, Cheung FM, Chow JC (2002) Transitional cell metaplasia of the uterine cervix is related to human papillomavirus: molecular analysis in seven patients with cytohistologic correlation. Cancer 96: $250-258$

Nobbenhuis MA, Helmerhorst TJ, van den Brule AJ, Rozendaal L, Voorhorst FJ, Bezemer PD, Verheijen RH, Meijer CJ (2001) Cytological regression and clearance of high-risk human papillomavirus in women with an abnormal cervical smear. Lancet 358: $1782-1783$

Park JS, Hwang ES, Park SN, Ahn HK, Um SJ, Kim CJ, Kim SJ, Namkoong SE (1997) Physical status and expression of HPV genes in cervical cancers. Gynecol Oncol 65: $121-129$

Roda Husman AM, Walboomers JM, van den Brule AJ, Meijer CJ, Snijders PJ (1995) The use of general primers GP5 and GP6 elongated at their 3' ends with adjacent highly conserved sequences improves human papillomavirus detection by PCR. J Gen Virol 76(Part 4): 1057 - 1062

Sotlar K, Selinka HC, Menton M, Kandolf R, Bultmann B (1998) Detection of human papillomavirus type 16 E6/E7 oncogene transcripts in dysplastic and nondysplastic cervical scrapes by nested RT-PCR. Gynecol Oncol 69: 114-121

Stoler MH, Rhodes CR, Whitbeck A, Wolinsky SM, Chow LT, Broker TR (1992) Human papillomavirus type 16 and 18 gene expression in cervical neoplasias. Hum Pathol 23: 117-128 
Walboomers JM, Jacobs MV, Manos MM, Bosch FX, Kummer JA, Shah KV, Snijders PJ, Peto J, Meijer CJ, Munoz N (1999) Human papillomavirus is a necessary cause of invasive cervical cancer worldwide. J Pathol 189: $12-19$

Zuna RE, Sienko A, Lightfoot S, Gaiser M (2002) Cervical smear interpretations in women with a histologic diagnosis of severe dysplasia: factors associated with discrepant interpretations. Cancer 96: $218-224$ zur Hausen H (1988) Papillomaviruses in human cancers. Mol Carcinog 1: $147-150$

zur Hausen H (1989) Host cell regulation of HPV transforming gene expression. Princess Takamatsu Symp 20: 207-219

zur Hausen H (1991) Human papillomaviruses in the pathogenesis of anogenital cancer. Virology 184: 9-13

zur Hausen H (2002) Papillomaviruses and cancer: from basic studies to clinical application. Nat Rev Cancer 2: $342-350$ 